\title{
Seasonal optimization of a dynamic thermo-optical ETFE façade system
}

\author{
Jung Min Han ${ }^{1}$, Daekwon Park ${ }^{2}$ \\ ${ }^{1}$ Harvard University Graduate School of Design, Cambridge, USA \\ ${ }^{2}$ Syracuse University School of Architecture, Syracuse, USA
}

\begin{abstract}
In typical high-rise commercial buildings in moderate climates such as that of New York City, over $50 \%$ of the annual electricity consumption is used for space cooling and heating (Kontokosta, 2007). Most of the cooling load in office buildings originates from solar heat gain on the building envelope. To date, passive solar heat gain and loss has been overlooked by researchers. Yet controlling solar radiation is important to reducing building energy consumption. Admittedly, ETFE membranes are increasingly being used in architecture in everything from extensive roofing to façade systems, due to their transparency and light weight. Research proposed by Park (2016) developed a lightweight and low-energy dynamic thermal insulation (DI) system for tall building envelopes. The system consists of a series of air cavities divided by ETFE membranes with a Low-E coating. The still air captured within the air-tight cavities functions as thermal insulation material, and radiant barrier films reduce radiant heat transfer through the air spaces. This system has the potential to save energy throughout the year because of its ability to consider seasonal variations. Importantly, the system is flexible enough to adequately adapt to future climate changes. By taking one representative future weather scenario as an example, the present parametric study was carried out on a DI system to investigate the adaptive building envelope and its impact on building performance. The results illustrate the effectiveness of the proposed envelope system with various U-values of heating and cooling load reductions, along with additional mitigation of the carbon footprint.
\end{abstract}

\section{Introduction}

According to the Intergovernmental Panel on Climate Change (IPCC), it is unequivocal that the Earth's climate is warming. The IPCC had shown that several types of extreme weather events have changed in frequency and intensity over the last 50 years (Taylor, 2008). These changes in weather patterns affect the energy consumption of buildings. Future adaptation and the evolution of building envelope design are necessary to aid in the development of climate-adaptable building projects. Due to current issues with building simulations, actual energy demands have consistently been growing, especially for buildings that consume more than $40 \%$ of the total energy (Amasyali and El-Gohary, 2018).

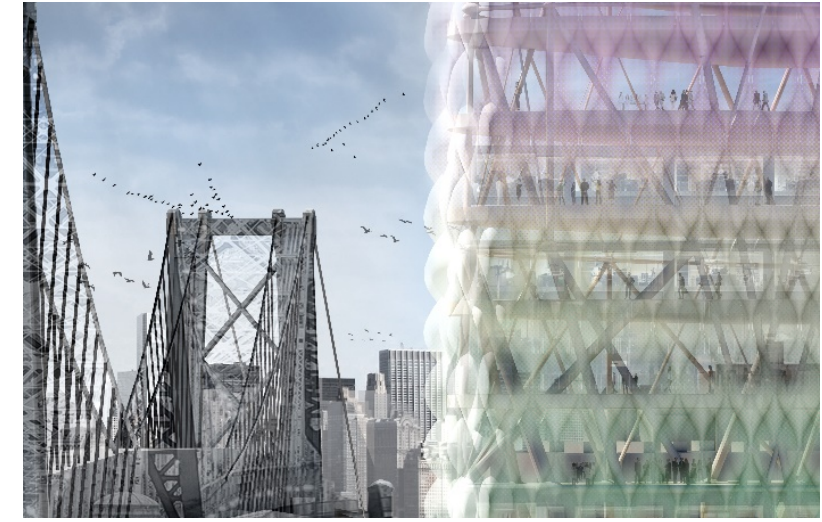

Figure 1: Conceptual rendering of ATSF.

An ETFE façade is a flexible, high-performance material used in the sustainability industry, and is closely related to building envelope performance and improvements in occupants' thermal comfort. The system can extend to the control system to further reduce energy consumption in buildings. The dynamic insulation (DI) of the facade and its operation are essential to implementing sustainable means of reducing building energy use. Due to the development of different materials with a variety of properties, one effective way of controlling thermal loss and gain in building envelopes may be discrete operations of façade properties by the rate of insulation level or solar heat gain coefficient.

The tuneable U-value façade system explored in this research is a type of DI system (see Figure 1). DI systems enable buildings to adapt to seasonal and diurnal climate changes. This feature can potentially contribute to energy savings during transition periods between heating and cooling of interior spaces. For example, during hot summer days, it may be beneficial to have a high degree of thermal insulation to prevent the outdoor heat from penetrating inside. However, during cool summer nights (such as in arid climates) when outdoor temperatures are lower, the heat trapped in the interior cannot transfer through the envelope because of its insulating properties. In this scenario, DI can reduce the thermal insulation capacity of the envelope and lower the required cooling load.

A multilayer ETFE construction with dynamic properties has the potential to be an effective response to climate conditions such as solar radiation, and thus positively affect the energy consumption of buildings. This research describes the design optimization and equivalent 
performance analysis of an adaptive ETFE façade system. This façade system is capable of dynamically adjusting its U-value (i.e., dynamic insulation) and solar heat gain coefficient (SHGC) based on diurnal and seasonal temperatures and solar information.

\section{Methodology}

Building performance simulations (BPS) are commonly used to predict building energy consumption, as well as occupants' visual comfort (Malkawi and Augenbroe, 2004). Through BPS, it is possible to optimize the annual energy consumption of buildings by controlling building attributes such as shading devices and window materials and their operation. This research examines a method of controlling ETFE facades, drawing on relevant simulation studies to change critical parameters such as the façade's U-value and building's physical attributes.

The subject building was a 40 -story commercial tower with approximately 200 occupants per floor, located in New York City (NYC), New York, USA.

\section{Weather file selection}

The EnergyPlus Weather Format (EPW) file is a file format that is widely used in current energy simulation practice; however, due to its limited and relatively outdated datasets, the existing EPW file is not ideal for optimizing envelope systems in response to present conditions. Use of the EPW file produces errors in energy simulations and misrepresentations of current climate changes such as global warming. Before establishing a baseline building for the parametric study, the weather file needed to be manipulated and estimations made according to a comparative analysis of the predicted weather data and forecasted real-time data for NYC (NREL, 2019).

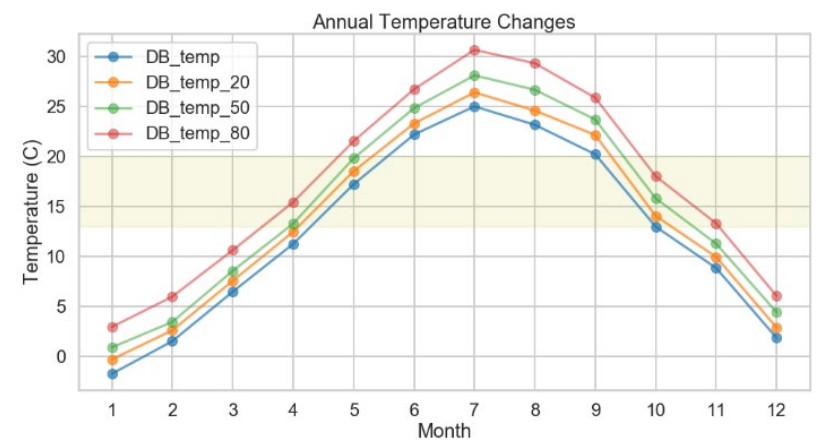

Figure 2: Monthly temperature variations on different dates.

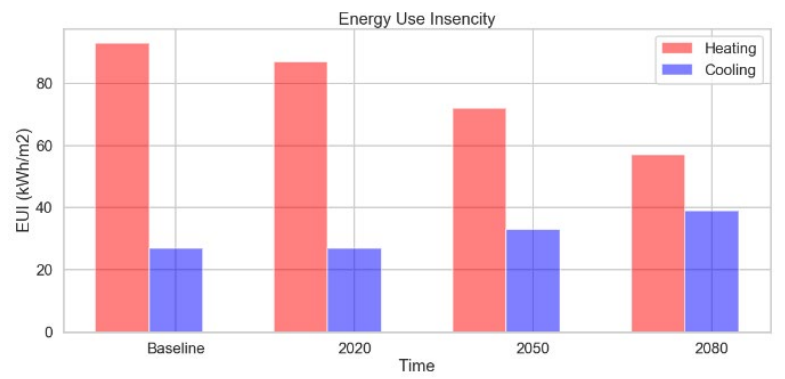

Figure 3: Heating and cooling load comparisons.

To accomplish this task, 2020, 2050, and 2080 predicted EPW weather files were generated from the current EPW file, using CCWorldWeatherGen (Jentsch et al., 2013); the results were then compared to the currently available weather data downloadable from the National Solar Radiation Database (NSRDB) (see Figure 2). The drybulb temperature and relative humidity were compared to obtain the closest predicted data. The 2020 prediction file was selected to serve as the baseline simulation weather data; the least root mean square error (RMSE) represented was 2.54. Figure 3 shows the changes in heating load from the baseline, information that can serve as an indicator when designing a building responsive to heating and cooling degree days. In our case, the design goal is to reduce the heating load during the winter actively by providing more direct sunlight on the buildings' façade. Note that, when design buildings in the future such as 2050 and 2080 the design goal will be differentiated to reduce cooling load during the summer.

After selecting the baseline weather file to represent the current local temperature in NYC, the annual energy consumption of the proposed building was calculated using the DOE reference model, with a large office building serving as a baseline. The baseline energy use intensity (EUI) and simulation assumptions are presented in the next section.

\section{Simulation description}

The goal was to analyse and predict the performance of the façade system at the overall building level, using computational building simulation tools such as DesignBuilder, EnergyPlus, and DIVA. The original design information, simulation settings, parameters, and assumptions involved in the simulation procedure were primarily based on existing documentation of a DOE reference building. Additionally, local regulations and ASHRAE standard instructions for a similar climate zone were applied when appropriate (i.e., US Zone 4A; Athalye, Taylor, and Liu, 2016). Several parametric studies are described herein as support for our proposal of the best-performing geometry and DI system.

A baseline envelope design was chosen after conducting a radiation analysis. While topo-optimization (see Figure 4; Park, 2016) provided the most desirable structural configuration among the various options, the radiation analysis facilitated the selection process of the final design by referencing the results of the optimized solar heat gain during winter (more than four hours a day in the worst-case scenario). Among the options (all with at least four hours of direct sunlight gain per day), Option 5 was selected due to the less-direct radiation gain on the southfacing façade during the summer. Figure 4 shows the annual direct sunlight exposure in each design iteration. The values were calculated by counting the number of ray hits on the façade, and the final design was selected based on less than $20 \%$ of the areas being under $10 \%$ in the worst case per day (Han, 2018). 


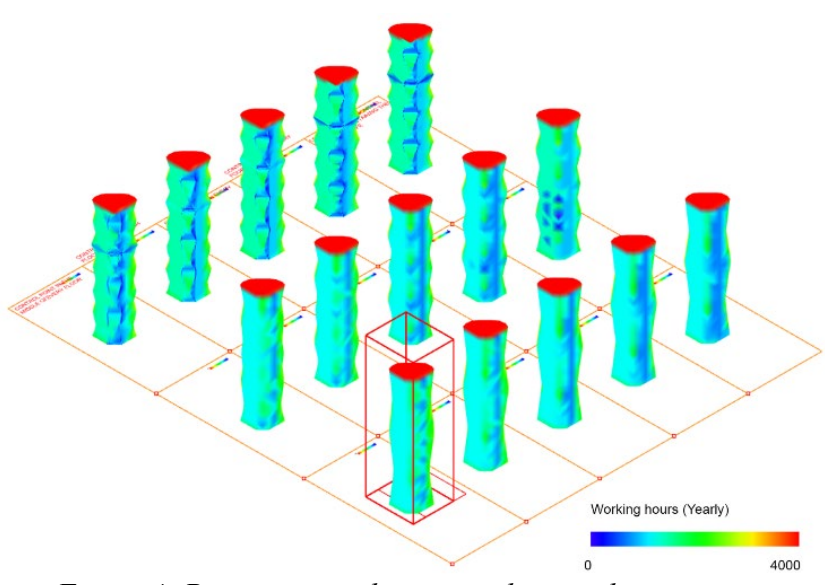

Figure 4: Parametric radiation analysis and geometry selection.

Once the building façade design was fixed, a BPS was created to design the best-performing building attributes, including aspects such as U-value and the SHGC of the DI material. This study used several commercial tools: Rhinoceros ${ }^{\circledR}$ for 3D modelling, and Grasshopper and DIVA for parametric daylighting analysis and façade design. For the energy-efficient building design, DesignBuilder (see Figure 5) and EnergyPlus were employed, along with multiple sets of parameters for the operation of the dynamic façade. The primary goal of this research was to minimize energy consumption during the critical seasons of the year.

\section{Energy simulation}

Figure 5 shows the baseline building geometry used for the energy simulation, and Table 1 illustrates all of the relevant input parameters for the annual electricity calculation.

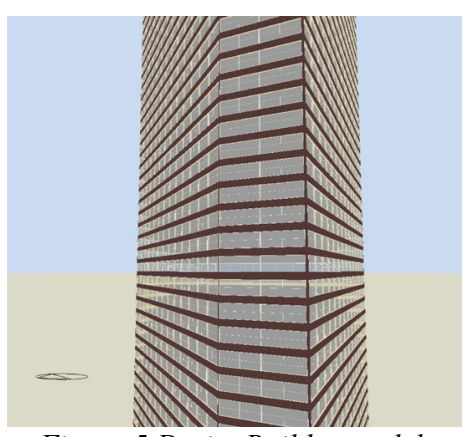

Figure 5 DesignBuilder model.

Table 1: Simulation Assumptions

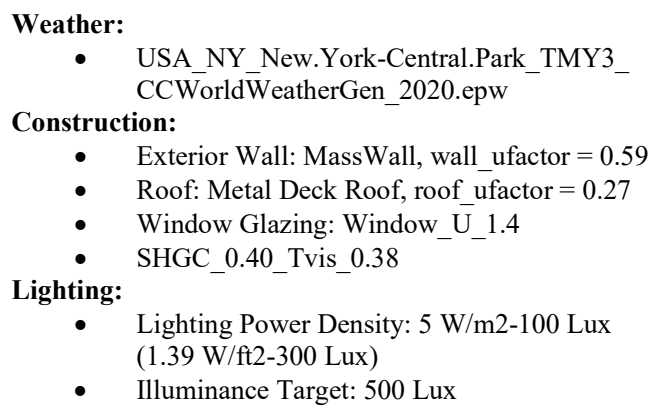

- Exterior Wall: MassWall, wall_ufactor $=0.59$

- $\quad$ Roof: Metal Deck Roof, roof_ufactor $=0.27$

- Window Glazing: Window_U__1.4

- $\quad$ SHGC_0.40_Tvis_0.38

- $\quad$ Lighting Power Density: $5 \mathrm{~W} / \mathrm{m} 2-100$ Lux (1.39 W/ft2-300 Lux)

- Illuminance Target: 500 Lux

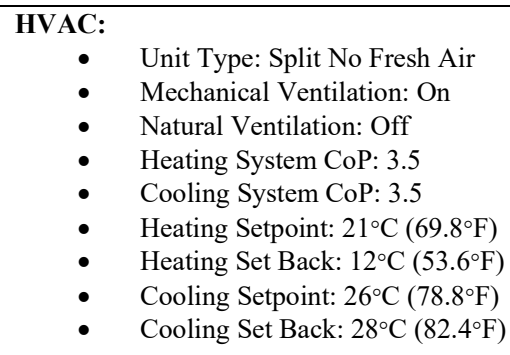

Detailed information regarding building occupancy and lighting schedule is listed in the description above. Once the DesignBuilder model was set, a building energy simulation was conducted. The initial value was later used for the parametric study as a relative value for estimating the building's performance improvement. The baseline model showed the average electricity consumption per $\mathrm{m}^{2}$ to be 185 . The separate heating and cooling energy consumptions, as well as the whole-building energy use, were simulated by season. Other parameters such as the occupants' activity and clothing level, wall/roof construction, internal gain, and system configuration were constant for each simulation, while the glazing configuration and its properties were changed in every iteration. The ultimate goal was to find the optimal Uvalues for each DI system in response to seasonal variations.

\section{Daylight simulation and operational schedule}

A great deal of research has underscored the importance of daylighting effectiveness in buildings. With respect to both energy savings and occupants' comfort, it is necessary that daylighting control be automated, based on dynamic control systems. Conventionally, blinds are controlled to block direct sunlight, based on predetermined guidelines such as the ASHRAE Fundamentals. A strict method for controlling shading devices in response to sunlight often results in an undesirable screening of daylight and views to the outside. The current state of the art in blinds control considers ways of controlling blinds that consider occupants' comfort and daylighting autonomy. Technical methods for controlling DI systems include automated control with fewer view obstructions. The amount of daylight penetration determines the DI system's controls. The daylight simulation described in the next section extends a new method of daylighting control that uses DI to maximize daylighting and view, while preventing glare. In other words, the original approach can be adapted to reduce cooling loads and enhance the level of natural sunlight entering buildings. The new method is meaningful in terms of enriching occupants' comfort and providing advantages associated with biophilia. In addition, it demonstrates future means of adapting buildings' façade systems with respect to reducing cooling loads during the summer and allowing more sunlight in during winter. 


\section{Performance Simulation}

\section{Window-to-wall ratio study}

In heating-dominated climates or where the heating load is a concern, a large window-to-wall ratio (WWR) helps to decrease annual heating loads while maintaining adequate comfort. A WWR parametric study was designed to reduce the heating load in winter and cooling load in summer, while maintaining the indoor temperature within a comfortable range. Among the tested ratios, an $80 \%$ WWR for the south and 60\% WWRs for the northeast and northwest façades were identified as consuming the least amount of EUI, including the lowest heating load for winter and cooling load for summer. According to the results of the annual energy simulation, the highest impact of the optimized WWR was on the heating load, reducing $35 \%$ of the total energy use; however, it also increased the cooling load during the summer. Therefore, to determine the best-performing building envelope systems, parametric runs of glazing properties with U-values between $0.4 \mathrm{~W} / \mathrm{m}^{2}{ }^{\circ} \mathrm{C}$ and 5.8 $\mathrm{W} / \mathrm{m}^{2}{ }^{\circ} \mathrm{C}$ at a subdivision of 0.2 were performed.

\section{U-value parametric simulation study}

Individual parametric studies were done to schedule the performance of an ETFE cushion in different seasons. This simulation was designed to evaluate the seasonal performance of windows comprised of different materials.

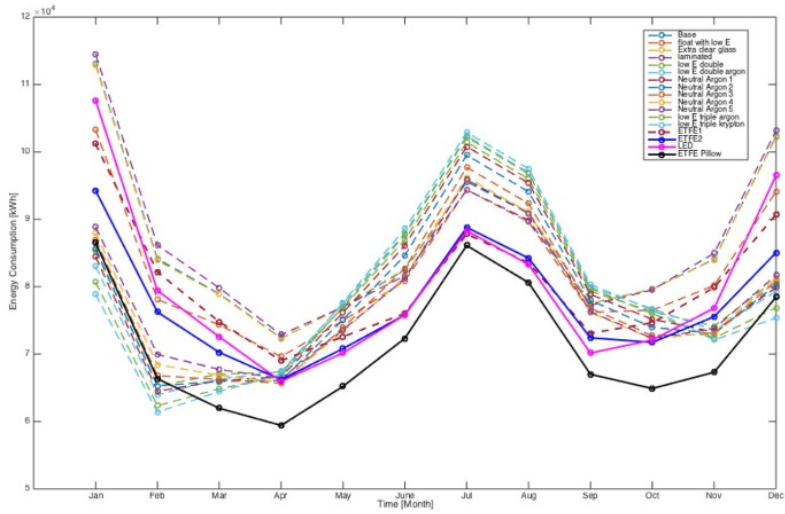

Figure 6: Monthly energy use of target building for different materials.

Table 2 illustrates the potential U-values for each system with discrete SHGC values. The different SHGCs are evaluated below, along with the daylighting simulations. Thus, this section limits this value for the performance simulation. Figure 8 shows the performance of the ETFE as compared to other window materials such as monolithic glass, double-glazed glass, and other highperformance glass and ETFE windows. The results illustrate the unique performance of the four-layer ETFE cushion throughout the year. Besides the overall performance of the ETFE system, the relatively low level of energy consumption during the winter by the proposed system is clear. This means that with DI systems, a heating load reduction could easily be achieved in both the winter and summer seasons.
Table 2: Simulation Assumptions for Different Materials

\begin{tabular}{|c|c|c|}
\hline Description & $\begin{array}{c}\text { U-value } \\
\text { (W/m2C) }\end{array}$ & SHGC \\
\hline 6mm monolithic glass & 5.9 & 0.95 \\
\hline 6-12-6 double-glazed unit & 2.8 & 0.83 \\
\hline $\begin{array}{c}\text { 6-12-6 high-performance } \\
\text { double-glazed unit }\end{array}$ & 2.0 & 0.35 \\
\cline { 1 - 2 } 2-layer ETFE cushion & 2.9 & $0.71-$ \\
\hline 3-layer ETFE cushion & 1.9 & 0.22 \\
\hline 4-layer ETFE cushion & 1.4 & \\
\hline
\end{tabular}

To propose a more specific operational schedule for the DI system, a step-by-step energy simulation was conducted via EnergyPlus. Figure 7 shows the annual variations in EUI by different U-values. The effectiveness of the EUI change is clear; the U-values were approximately $2.0 \mathrm{~W} / \mathrm{m}^{2}{ }^{\circ} \mathrm{C}$ and $3.2 \mathrm{~W} / \mathrm{m}^{2}{ }^{\circ} \mathrm{C}$. This can be used as a reference for different seasonal designs for ETFE systems.

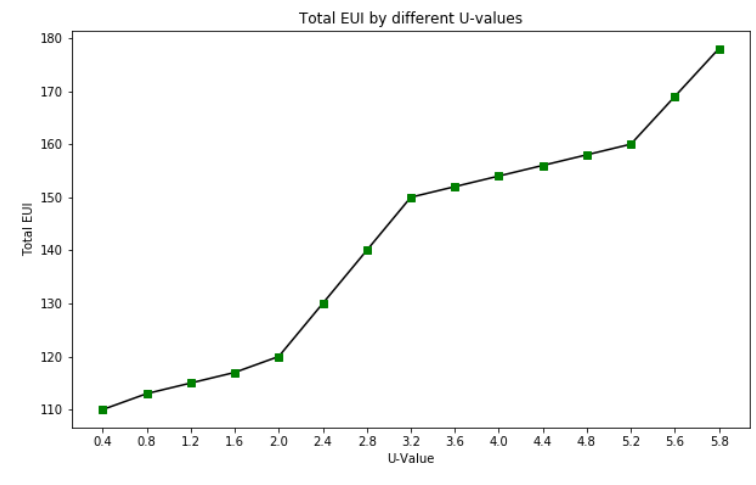

Figure 7: U-value parametric simulation.

The diagram below shows the dynamic operation of a different phase of ETFE cushion with U-values ranging from $0.4 \mathrm{~W} / \mathrm{m}^{2}{ }^{\circ} \mathrm{C}$ to $5.8 \mathrm{~W} / \mathrm{m}^{2}{ }^{\circ} \mathrm{C}$. Again, the goal of this study is to provide an operational schedule for an ETFE that is less than the total EUI of 160.

\section{Results}

\section{Energy analysis}

An optimized schedule was developed by evaluating the radiation levels during critical seasons: summer, winter, and warm and cool swing seasons. Each season's EUI was calculated separately.

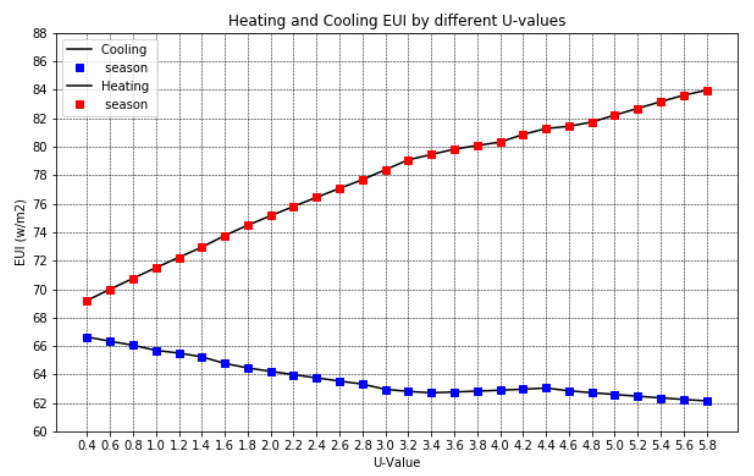

Figure 8: Parametric graph of seasonal U-values.

Figure 10 shows the heating and cooling loads produced by different $\mathrm{U}$-values, which are refererenced in the following section. The U-values at $1.8 \mathrm{~W} / \mathrm{m}^{2}{ }^{\circ} \mathrm{C}, 3.2$ 
$\mathrm{W} / \mathrm{m}^{2}{ }^{\circ} \mathrm{C}$, and $4.8 \mathrm{~W} / \mathrm{m}^{2}{ }^{\circ} \mathrm{C}$ represent slightly different trends in internal load calculation, yielding peaks at 0.4 $\mathrm{W} / \mathrm{m}^{2}{ }^{\circ} \mathrm{C}$ and $5.8 \mathrm{~W} / \mathrm{m}^{2}{ }^{\circ} \mathrm{C}$, respectively. Thus, these values could be simulated for the total EUI calculation.

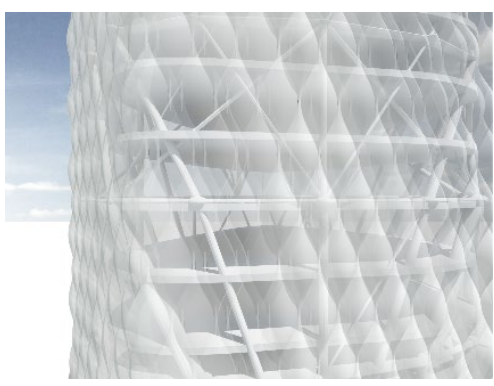

DI system in swing season

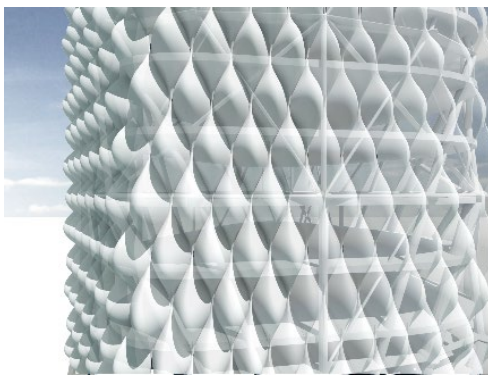

DI system in cooling season

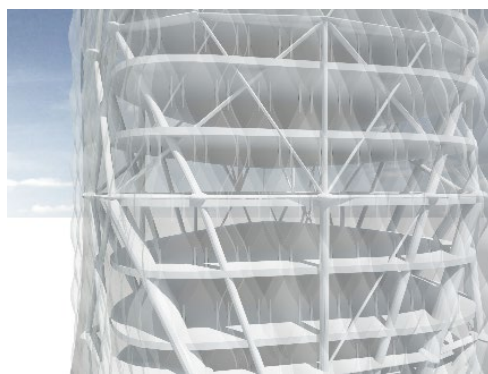

DI system in heating season

Figure 9: Proposed U-values by season.

Figure 9 illustrates the range of $U$-values for the seasonal and diurnal operational façade schedule. The proposed range was optimized for the 2020 weather file, but could be adjusted in the future for annual surface solar radiation prediction values.

A comprehensive control logic for EFTE façade operation was developed in response to the results of the parametric study (see Figure 10). When the level of target radiation exceeded $80 \%$ of the daily average value, the U-value properties of the ETFE cushions inflated. When the level of target radiation was below $50 \%$ of the daily average value, the U-value properties of the ETFE cushions deflated to allow more radiation to penetrate indoors.

The schedule for the EFTE flattening rate and time of day are illustrated and the schematic diagram and operation controls are presented below, based on the fraction of radiation exposure.

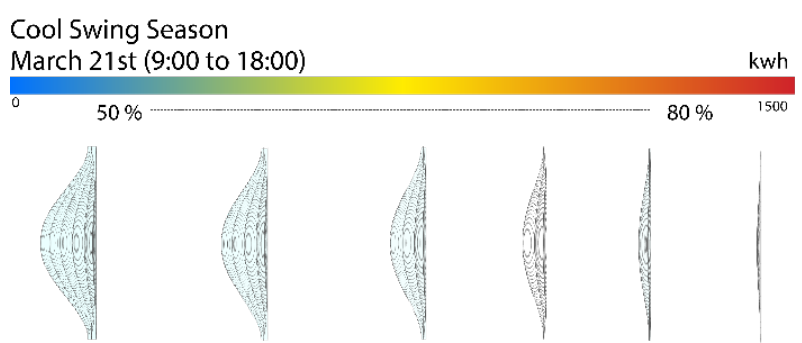

Summer Season

June 21st (9:00 to 18:00) kwh

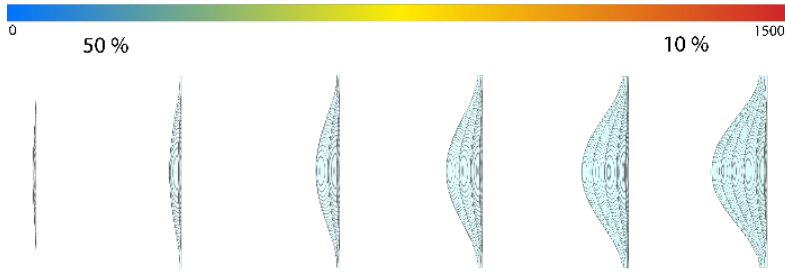

Warm Swing Season

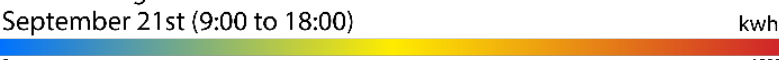

$90 \%$

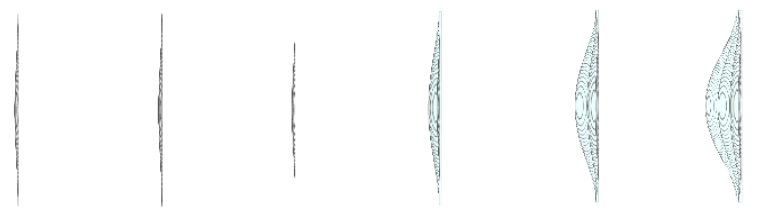

Winter Season

December 21 st (9:00 to $18: 00)$

$50 \%$

$90 \%$

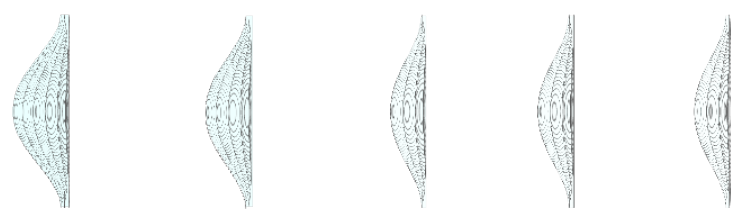

Figure 10: Seasonal operation schedule.

Figure 10 delineates the conceptual operation of the DI system, with different rates of inflation and deflation. The inflation rates govern the U-value and SHGC. Hence, visual comfort and daylighting penetration can also be considered with the operational schedule.

\section{Daylighting analysis}

With an advanced daylighting simulation in DIVA for Rhino (Solemma 2014), annual sunlight exposure (ASE) can be achieved in no more than $10 \%$ of the regularly occupied space, with $55 \%$ of the spatial daylight autonomy (SDA) at the target lux of 300. Since it is difficult to simulate the proposed DI system's operational schedule in DIVA, an alternate method was used in the present research. First, we defined the shading schedule with translucent roller shades and manually added shading geometry to simulate the daily operation of the DI system. 


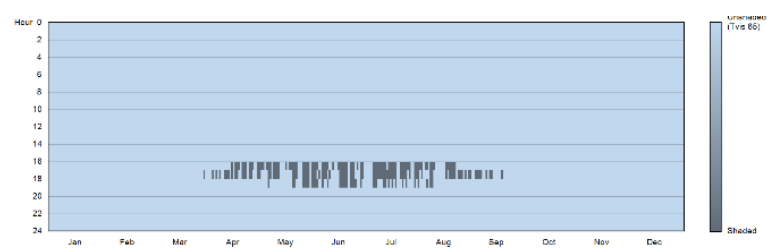

Seasonal automatic control of the DI system

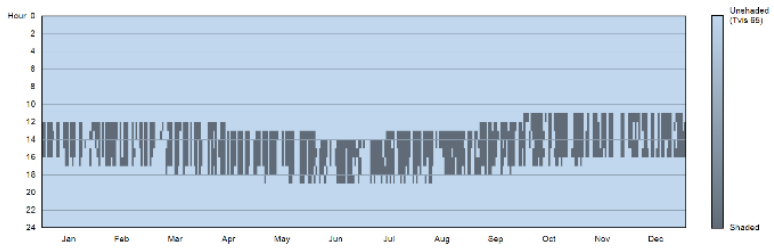

Detailed daily schedule for the DI system

Figure 12: Applied control system and schedule.

The optimized option for winter yielded an sDA of $77 \%$ for the year, while the optimized option for summer produced an SDA of $56 \%$ annually (see Figure 12 ). This is because the capacity for injecting fog inside the ETFE tubes increased, Thus, we could obtain the average T-vis for each option, which varied between 20 and 45 .
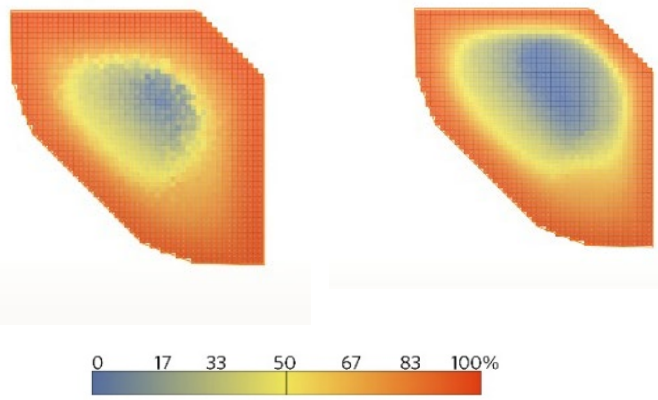

Figure 12: Spatial daylight autonomy before and after control.

Figure 13 shows the discomfort glare probability for the model at a representative desk on the southwest façade. In general, southwest façades in offices in similar climate zones have an afternoon glare problem. Therefore, a sample desk space was chosen to evaluate the effectiveness of the ETFE façade in terms of the glare metrics for reduction in discomfort. December at $2 \mathrm{pm}$ was tested as an example case, since the highest visible transmittance is maintained during the winter. At a given point in time, the level of intolerable glare in the workspace was at $57 \%$ without daily operation of the DI system. However, day-to-day control of the DI system reduced the glare problem from $57 \%$ to $33 \%$ in the critical hours of the day.
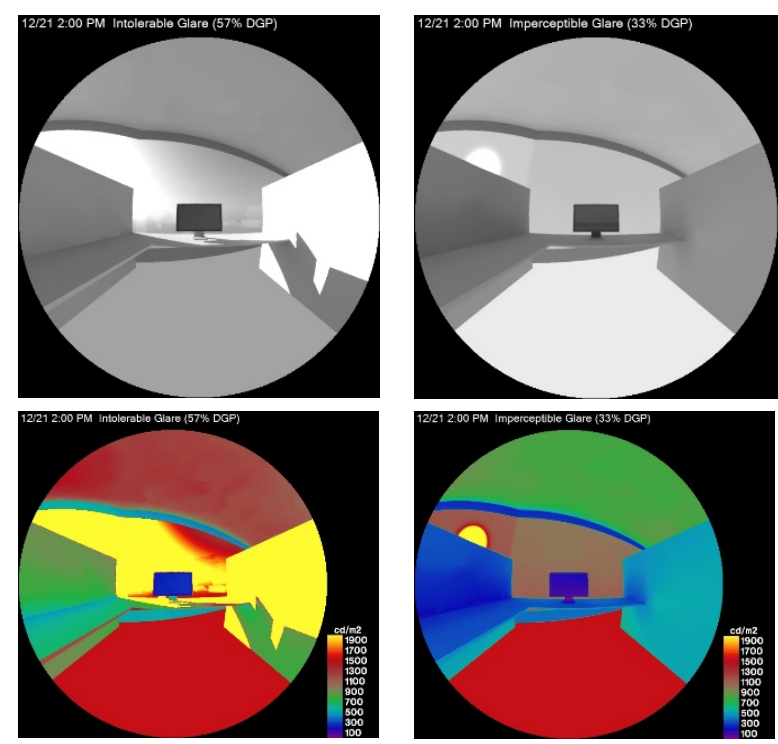

Figure 13: Glare reduction by daily operation of the DI.

Finally, to reduce the cooling load, a dynamic facade performance simulation was conducted to delineate a feasible range of $U$-values in the facades. Based on the results of the parametric studies, the U-values at $1.8 \mathrm{~W} / \mathrm{m}^{2}$ ${ }^{\circ} \mathrm{C}$ in summer and $0.4 \mathrm{~W} / \mathrm{m}^{2}{ }^{\circ} \mathrm{C}$ in winter showed the best energy performances in terms of EUI. When compared to the annual energy consumption of the baseline, the EUI of the base case with U-values of $5.8 \mathrm{~W} / \mathrm{m}^{2}{ }^{\circ} \mathrm{C}$ and 0.4 $\mathrm{W} / \mathrm{m}^{2}{ }^{\circ} \mathrm{C}$ in the heating and cooling seasons, respectively, was $110 \mathrm{~W} / \mathrm{m}^{2}$; the optimized model showed a $22 \%$ reduction in EUI at $86 \mathrm{~W} / \mathrm{m}^{2}$ by adjusting the SHGC and $\mathrm{T}$-vis values in different seasons.

Consequently, a total reduction of $49 \%$ of the total EUI was achieved by conducting radiation and energy optimization studies. In addition, the final EUI result was lower than the benchmarking data for best-practice large offices in NYC, which were at 130 to $150 \mathrm{~W} / \mathrm{m}^{2}$.

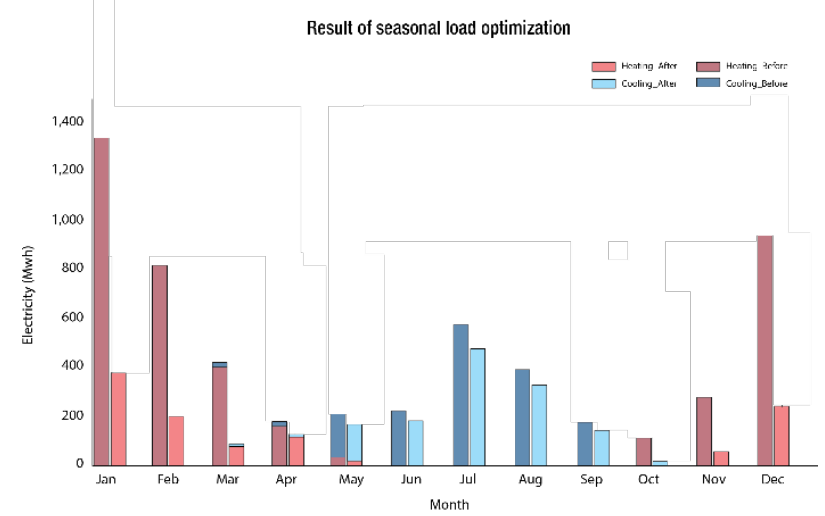

Figure 14: Seasonal energy load simulation results. 


\section{Discussion}

DI systems can contribute significantly to energy savings in commercial buildings by dynamically controlling the U-value of building envelopes, based on seasonal climate variations, diurnal temperature swings, and façade orientation. The operating principle is to control the thickness of the air cavity layer via inflation, in order to achieve the target thermal function. The U-value is at its minimum (i.e., thermal insulation) at optimum air cavity thicknesses that suppress air convection and maximum (i.e., heat exchanger) when the air cavities are collapsed into a single membrane.

The preliminary study conducted by Park (2016) indicated that a system using a radiant barrier can achieve better insulation values than mineral wool or fiberglass insulation, while requiring significantly less material and overall thickness (e.g., $72 \mathrm{~mm}$ instead of $140 \mathrm{~mm}$ to achieve a U-value of $0.35 \mathrm{~W} / \mathrm{m}^{2} \mathrm{~K}$ ). Also, the energy simulation study examining a proposed high-rise building in New York City using the optimum U-values for summer and winter showed that it is possible to reduce the total energy use by $56 \%$ for heating and $26 \%$ for cooling, in total consuming only $70 \%$ of the total energy of a similar scale (i.e., a typical large office building in New York City). Moreover, the present research emphasizes the effectiveness of DI for reducing building energy consumption by providing design strategies that employ this technology.

In heating-dominant climates, the balance between HVAC operation schedule and free-cooling (i.e., air-side economizer) operation periods is important to ensuring occupants' thermal comfort in large office buildings. The proposed dynamic façade includes an operation schedule, the material properties of the ETFE cushions, and the envelope system. The table of various U-values provides the performance simulation results, which is the primary factor in annual heating and cooling energy use. A total reduction in fuel consumption to $56 \%$ of heating and $26 \%$ of cooling was achieved by applying the dynamic façade system (see Figure 13) to the proposed building configuration. This is equivalent to an annual carbon emission of 2,553.79 tons. As compared to the benchmarking data, our final design consumed less than the total energy of the best-practice buildings in NYC (i.e., the building performance database average value). The results of each upgrade in building energy simulation demonstrate the improvement in the envelope system in terms of both efficiency and economics.

Because the overall WWR of the proposed design is higher than that of the DOE reference building, the cooling load reduction was not as significant as that of the heating load. Therefore, natural ventilation and an HVAC system upgrade are recommended for future consideration. In addition, this dynamic envelope system has the potential to control indoor lighting loads, which consume $25 \%$ of the total energy use in large office buildings. By controlling the SHGC and T-vis values of the ETFE system, occupants' thermal and visual comfort (as measured by daily comfort criteria) are ensured.

\section{Conclusions and Future Research}

With the growing concern regarding climate change, adaptive façades are increasingly being investigated; many of these studies used building energy simulation. The gaps in average temperature fluctuation during the different seasons comprise the main issue affecting the regulation of facade schedules. Therefore, we proposed varied level of U-values of DI systems in different seasons, and simulated energy savings throughout a year. Additionally, DGP was calculated in the representative desk space on the point in time of the critical season to ensure occupants visual comfort at workstations.

Future work will focus on implementing variable solar heat gain coefficient and visible transmittance control functions into the DI system. This could be automated with a concise schedule and the operational control system. This functionality of control of DI system will have a significant impact on building energy performance because indoor artificial lighting loads can be as high as $25 \%$ of the total energy used in large office buildings. Furthermore, it will be interesting to inject different color pigments to the gases in air cavity to satisfy humans' visual sensations and regulate a circadian rhythm which is becoming an issue in well-living lifestyle.

\section{References}

Amasyali, K. and El-Gohary, N. M. (2016). A review of data-driven building energy consumption prediction studies. Renewable and Sustainable Energy Reviews, 81, 1192-1205.

Athalye, R., Taylor, T., and Liu, B. (2016). Impact of ASHRAE Standard 169-2013 on building energy codes and energy efficiency. ASHRAE Transactions, 431-438.

Han, J. M. (2018). Eabbit 1.0: New environmental analysis software for solar energy representation. In $16^{\text {th }}$ IBPSA International Conference and Exhibition, Rome.

Jentsch, M. F., James, P. A., Bourikas, L., and Bahaj, A. S. (2013). Transforming existing weather data for worldwide locations to enable energy and building performance simulation under future climates. Renewable Energy, 55, 514-524.

Park, D. (2016). Multiscale Thermal Design for Buildings. Chapter 7. Thermally Augmented Building Envelope System. Doctoral dissertation, Harvard University.

Kontokosta, D. C. E. (2007). New York City Energy \& Water Performance Map. Retrieved from https://serv.cusp.nyu.edu/projects/evt/

Malkawi, A. and Augenbroe, G. (2004). Advanced Building Simulation. Routledge.

NREL. (2019). NSRDB: Solar radiation database. Retrieved from https://nsrdb.nrel.gov/apiinstructions

Taylor, Z. T. (2008). Climate Change Impacts on Residential and Commercial Loads in the Western U . S . Grid. Contract. 